\title{
Estrogen Maintains Trabecular Bone Volume in Rats Not Only by Suppression of Bone Resorption but Also by Stimulation of Bone Formation
}

\author{
J. Chow, J. H. Tobias, K. W. Colston, * and T. J. Chambers \\ Departments of Histopathology and Chemical Pathology, St. George's Hospital Medical School, London, SW17 ORE, United Kingdom
}

\begin{abstract}
Estrogen is generally considered to maintain bone mass through suppression of bone resorption. We have previously demonstrated that administration of pharmacologic doses of estrogen increases bone formation in ovary-intact rats. To assess the effects of physiological concentrations of estrogen on bone formation, estrogen was administered to ovariectomized rats in which bone resorption was suppressed by the bisphosphonate 3-amino-1-hydroxypropylidene-1-bisphosphonate (AHPrBP). Animals receiving exogenous 17 $\beta$-estradiol $\left(E_{2}\right)$ $(1,10$, and $100 \mu \mathrm{g} / \mathrm{kg}$ daily for $17 \mathrm{~d})$ showed a dose-dependent increase in trabecular bone volume of $1.9,25.8$, and $43.6 \%$, respectively, compared with those rats treated with AHPrBP alone. The increase in bone volume was associated with an increase in bone formation in $\mathbf{E}_{\mathbf{2}}$-treated animals, in which bone resorption had been almost completely suppressed by AHPrBP. Neither ovariectomy, AHPrBP, nor $\mathbf{E}_{2}$ treatment had a significant effect on the volume or rate of formation of cortical bone. Thus, the increased bone resorption, which is a consequence of estrogen-deficiency, entrains increased bone formation, which masks a simultaneous reduction in estrogendependent bone formation. Therefore, in addition to the nonspecific effect of estrogen to depress formation via coupling, we have identified a specific effect of estrogen to increase formation independent of coupling. Thus it appears that estrogen maintains bone volume not only through inhibition of bone resorption, but also through stimulation of bone formation. ( $J$. Clin. Invest. 1992. 89:74-78.) Key words: bisphosphonate • estradiol • bone anabolism • osteoporosis • histomorphometry
\end{abstract}

\section{Introduction}

A reduction in estrogen levels after menopause is thought to be responsible for the accelerated bone loss $(1,2)$ and increased risk of sustaining osteoporotic fractures $(3,4)$ found in postmenopausal women. The bone loss of estrogen deficiency is attributable to an increase in bone resorption, together with a smaller increase in bone formation: indices of both formation and resorption are suppressed by replacement concentrations of estrogen, and further bone loss is prevented (5-8). Thus, estrogen is generally considered to maintain bone mass

Address correspondence to T. J. Chambers, M.D., Department of Histopathology, St. George's Hospital Medical, Cranmer Terrace, London, SW17 ORE, United Kingdom.

Received for publication 1 May 1991 and in revised form 16 September 1991 .

J. Clin. Invest.

(c) The American Society for Clinical Investigation, Inc.

0021-9738/92/01/0074/05 \$2.00

Volume 89, January 1992, 74-78 through an antiresorptive mechanism. This antiresorptive effect has recently been shown to be explicable as a direct effect of estrogen on bone $(9,10)$, in which estrogen induces cells of the osteoblastic lineage to inhibit osteoclastic bone resorption (11).

The effects of estrogen on bone formation seem paradoxical for a hormone that maintains bone mass, but are generally presumed to be the consequence of the mechanism that couples bone formation to bone resorption, such that suppression of bone resorption also suppresses bone formation (12). These resorption-induced changes in bone formation may mask an independent and distinct effect of estrogen on bone formation.

We have recently found that administration of pharmacological doses of estrogen, sufficient to raise concentrations to those seen in late pregnancy, increase bone formation above the rates observed in rats with physiological (nonpregnant) estrogen levels (13). In this study, we assess the effects of physiological levels of estrogen on bone formation. To do this, we reduced estrogen levels to below normal by ovariectomy. Because the increased bone resorption (a consequence of ovariectomy) itself increases bone formation, resorption was suppressed by a bisphosphonate. This has enabled us to identify a stimulatory effect of estrogen replacement on bone formation, distinct from the indirect inhibition of bone formation caused by estrogen replacement, that occurs through suppression of bone resorption by estrogen.

\section{Methods}

42 8-wk-old female Wistar rats, weighing 245 g each (range 210-275 g), were purchased from Interfauna UK Ltd., Huntingdon, UK. 36 of these had been ovariectomized and 6 were sham ovariectomized. During the period of the experiment, the animals were housed in groups of six at $21^{\circ} \mathrm{C}$ with a 12 -h light/12-h dark cycle. Food and water were given ad lib. to all animals, except ovariectomized animals not on $E_{2}$ treatment, which were pair fed. Food consisted of a maintenance diet (RMI; SDS, Witham, UK). $3 \mathrm{~d}$ after surgery, four ovariectomized groups of animals were given a single subcutaneous dose of AHPrBP (3-amino-1-hydroxypropylidene-1-bisphosphonate) ${ }^{1}(0.1 \mathrm{mg} \mathrm{P} / \mathrm{kg}$, Yamanouchi Pharmaceutical Co, Japan) in normal saline buffered to pH 7.4. The sham-ovariectomized group and one group of ovariectomized animals were given saline vehicle. This was taken as day 1 . Three of the ovariectomized groups were given daily subcutaneous injections of 1,10 , and $100 \mu \mathrm{g} / \mathrm{kg} 17 \beta$-estradiol $\left(\mathrm{E}_{2}\right)$ (Sigma Chemical Co., Poole, UK), respectively in $0.25 \mathrm{ml}$ of $5 \%$ benzyl alcohol/95\% corn oil (Sigma) for $17 \mathrm{~d}$. The remaining groups received $0.25 \mathrm{ml} 5 \%$ benzyl alcohol/ 95\% corn oil vehicle. Details of the experimental groups and protocol are summarized in Table I. Calcein $(30 \mathrm{mg} / \mathrm{kg}$; Sigma) and tetracycline hydrochloride ( $20 \mathrm{mg} / \mathrm{kg}$; Lederle Laboratory, Gosport, UK) were injected intraperitoneally 12 and $6 \mathrm{~d}$ before killing, respectively. $24 \mathrm{~h}$ after the final injection of the experimental agent, the animals were anesthetized with halothane, weighed, bled by cardiac puncture, and then killed by cervical dislocation. At autopsy, success of the ovariecto-

1. Abbreviations used in this paper: AHPrBP, 3-amino-1-hydroxypropylidene-1-bisphosphonate; $E_{2}$, estradiol. 
Table I. Experimental Protocol

\begin{tabular}{|c|c|}
\hline Group & Treatment \\
\hline Control & $\begin{array}{l}\text { Saline vehicle day } 1 \text { and corn oil } \\
\text { vehicle daily for } 17 d\end{array}$ \\
\hline Ox & $\begin{array}{l}\text { Saline vehicle day } 1 \text { and corn oil } \\
\text { vehicle daily for } 17 \mathrm{~d}\end{array}$ \\
\hline Ox + AHPrBP & $\begin{array}{l}\text { AHPrBP }(0.1 \mathrm{mg} \mathrm{P} / \mathrm{kg}) \text { day } 1 \text { and } \\
\text { corn oil vehicle daily for } 17 \mathrm{~d}\end{array}$ \\
\hline $\mathrm{Ox}+\mathrm{AHPrBP}+1 \mu \mathrm{g} \mathrm{E}_{2}$ & $\begin{array}{l}\operatorname{AHPrBP}(0.1 \mathrm{mg} \mathrm{P} / \mathrm{kg}) \text { day } 1 \text { and } \\
1 \mu \mathrm{g} \mathrm{E} \mathrm{E}_{2} / \mathrm{kg} \text { daily for } 17 \mathrm{~d}\end{array}$ \\
\hline $\mathrm{Ox}+\mathrm{AHPrBP}+10 \mu \mathrm{g} \mathrm{E}$ & $\begin{array}{l}\operatorname{AHPrBP}(0.1 \mathrm{mg} \mathrm{P} / \mathrm{kg}) \text { day } 1 \text { and } \\
10 \mu \mathrm{g} \mathrm{E} / / \mathrm{kg} \text { daily for } 17 \mathrm{~d}\end{array}$ \\
\hline $\mathrm{Ox}+\mathrm{AHPrBP}+100 \mu \mathrm{g} \mathrm{E}_{2}$ & $\begin{array}{l}\operatorname{AHPrBP}(0.1 \mathrm{mg} \mathrm{P} / \mathrm{kg}) \text { day } 1 \text { and } \\
100 \mu \mathrm{g} \mathrm{E}_{2} / \mathrm{kg} \text { daily for } 17 \mathrm{~d}\end{array}$ \\
\hline
\end{tabular}

mies was confirmed by absence of ovaries and atrophy of uteri in rats not given estrogen therapy. Uteri were removed and weighed. Serum levels of $E_{2}$ were measured by RIA (Coat-a-Count; Diagnostic Products Ltd., Abingdon, UK). The lower limit of sensitivity of this assay is 8 $\mathrm{pg} / \mathrm{ml} \mathrm{E}_{2}$.

The right tibia was removed and freed of soft tissue. It was then divided into an 8-mm diaphyseal section just proximal to the distal tibio-fibular anastomosis, and a second section that comprised the proximal metaphysis and epiphysis. These were fixed in $70 \%$ alcohol for $48 \mathrm{~h}$, dehydrated through graded alcohols and embedded undecalcified in London resin (London Resin Co. Ltd, Basingstoke, UK). Longitudinal sections of the proximal metaphysis $5 \mu$ thick were cut and stained with von Kossa and toluidine blue. Unstained sections $12 \mu \mathrm{m}$ thick were also cut. Cross sections of the tibial shaft were cut with a low speed diamond saw at $250 \mu \mathrm{m}$ and hand ground to $100-120 \mu \mathrm{m}$. Unstained sections for assessing fluorochrome labeling and sections stained with toluidine blue were examined.

Bone histomorphometry was performed using a light microscope linked to an Optomax (Analytical Measuring System Ltd., Cambridge, UK). Bone volume and surface parameters were obtained by tracing relevant surfaces with a cursor on the video screen image using an automated and semiautomated mode, respectively. All sections were examined blind.

Bone volume of the proximal metaphyseal cancellous bone was measured on three nonconsecutive serial sections stained with von Kossa at a magnification of 100 . A standard area of three adjacent frames $\left(0.78 \mathrm{~mm}^{2}\right.$ each $)$ in the vertical axis situated at least $1 \mathrm{~mm}$ from the growth plate to exclude the primary spongiosa was used $(8,10)$. Bone volume was defined as the percentage of metaphyseal bone area that consisted of bone. Surface parameters were measured in two sections stained with toluidine blue at a magnification of 200 . A standard area of 18 frames ( 3 parallel to the growth plate and 6 in the vertical axis), measuring $0.18 \mathrm{~mm}^{2}$ each, located in the secondary spongiosa in a corresponding area to that used for assessing bone volume, was used.
Surface parameters measured were as follows: $(a)$ osteoblast surface (OS/BS [\%]); (b) osteoclast surface (OcS/BS [\%]); (c) number of osteoclasts per $\mathrm{mm}$ of bone surface (N Oc/BS $[\mathrm{n} / \mathrm{mm}]$ ). Fluorochrome measurements were made on unstained $10-15-\mu \mathrm{m}$-thick sections of the same area. Longitudinal bone growth was derived as follows. The distance between the tetracycline band that parallels the growth plate and the growth plate-metaphyseal junction was measured, and divided by the time interval between the tetracycline label and death. The percentage of trabecular surface with a double fluorochrome label was measured as for the other surface parameters. Mineral apposition rate was the interlabel distance divided by the time interval (days) between their administration. The bone formation rate (tissue level, total surface referent) was obtained from the product of the mineral apposition rate and the percentage of trabecular surface covered in double label. Values for the apposition rate were not corrected for the obliquity of plane of section of trabecular bone.

The parameters measured on the shaft cross sections made on two stained and two unstained sections were the cross-sectional area, medullary area, cortical area (cross-sectional area minus medullary area), percentage of double-labeled surface on the periosteal and cortico-endosteal surfaces, and interlabel distances on these two envelopes. The mineral apposition rates and bone formation rates were calculated in a similar way to the metaphyseal trabecular bone.

Results from biochemical and histomorphometric analysis are expressed as the mean \pm SEM. Statistical analysis was performed by Fisher's least significant difference method for multiple comparisons in a one-way analysis of variance with Apple software (Statview 1.02; Abacus Concepts Inc., Cupertino, CA). Statistical significance was considered at $P<0.05$.

\section{Results}

\section{Systemic changes}

At the end of the experiment, the ovariectomized animals not on $\mathrm{E}_{2}$ treatment showed an increase in body weight compared with controls despite pair feeding. The uteri of these animals were markedly atrophic, apart from those given $E_{2}$, which restored the size to that of controls (Table II). The serum $\mathrm{E}_{2}$ measurements also confirmed the effect of ovariectomy and that of estrogen treatment.

\section{Bone histomorphometry}

Proximal metaphysis. Ovariectomy caused a substantial decrease in bone volume, which was prevented by AHPrBP (Fig. 1). We found that the bone volume was increased by $1.9,25.8$, and $43.6 \%$ in animals treated with 1,10 , and $100 \mu \mathrm{g} / \mathrm{kg} \mathrm{E} \mathrm{E}_{2}$, respectively, compared with ovariectomized animals given AHPrBP alone (Fig. 1). This increase in bone volume with the two higher doses was significant compared with the bone volume of rats treated with AHPrBP alone.

Bone turnover was increased by ovariectomy, as reflected by a twofold increase in the double-labeled bone surface. This

Table II. Body and Uterine Weights, and Serum $E_{2}$ Levels of Groups

\begin{tabular}{|c|c|c|c|c|c|c|}
\hline & \multicolumn{6}{|c|}{ Groups } \\
\hline & Control & Ox & Ox + AHPrBP & $\mathrm{Ox}+\mathrm{AHPrBP}+1 \mu \mathrm{g} \mathrm{E}_{2}$ & $\mathrm{Ox}+\mathrm{AHPrBP}+10 \mu \mathrm{g} \mathrm{E}_{2}$ & Ox + AHPrBP $+100 \mu \mathrm{g} E_{2}$ \\
\hline Final body weight (g) & $272.8 \pm 6.5$ & $283 \pm 9.9$ & $296.7 \pm 7.2^{*}$ & $292 \pm 9.6$ & $276.3 \pm 8.1$ & $288 \pm 5.1$ \\
\hline Uterine weight $(\mathrm{g})$ & $0.47 \pm 0.03$ & $0.13 \pm 0.01^{*}$ & $0.13 \pm 0.01^{*}$ & $0.42 \pm 0.04$ & $0.49 \pm 0.04$ & $0.51 \pm 0.05$ \\
\hline $\mathrm{E}_{2}(\mathrm{pg} / \mathrm{ml})$ & $14.0 \pm 6.1$ & $<8$ & $<8$ & $<8$ & $16.3 \pm 6.0$ & $20.3 \pm 8.2$ \\
\hline
\end{tabular}

Results are expressed in mean \pm SEM. * Significantly $(P<0.05)$ different from control. 


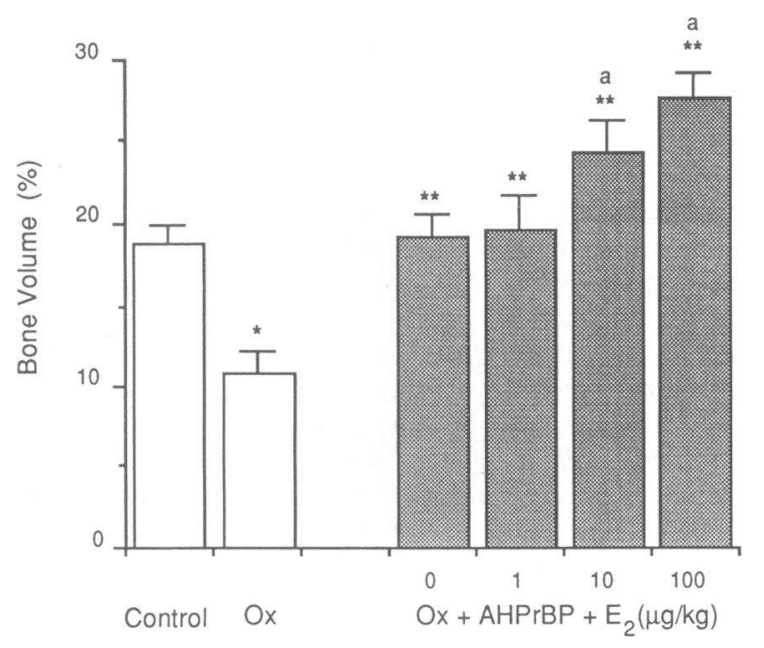

Figure 1. Effect of ovariectomy (Ox), AHPrBP, and $\mathrm{E}_{2}$ on bone volume at the proximal tibial metaphysis. Results are expressed in mean \pm SEM. *Significantly $(P<0.05)$ different from control; ${ }^{* *}$ significantly $(P<0.05)$ different from $O x ;$ a, significantly $(P<0.05)$ different from $\mathrm{Ox}+\mathrm{AHPrBP}$.

was strongly inhibited by administration of AHPrBP (Fig. 2). The increase in bone volume in animals treated with $\mathrm{E}_{2}$ was due to a marked increase in the mineral apposition rate and percentage of double-labeled surface, both of which were signifcantly different in the groups treated with 10 and $100 \mu \mathrm{g} \mathrm{E}_{2}$ compared with AHPrBP alone (Table III). The bone formation

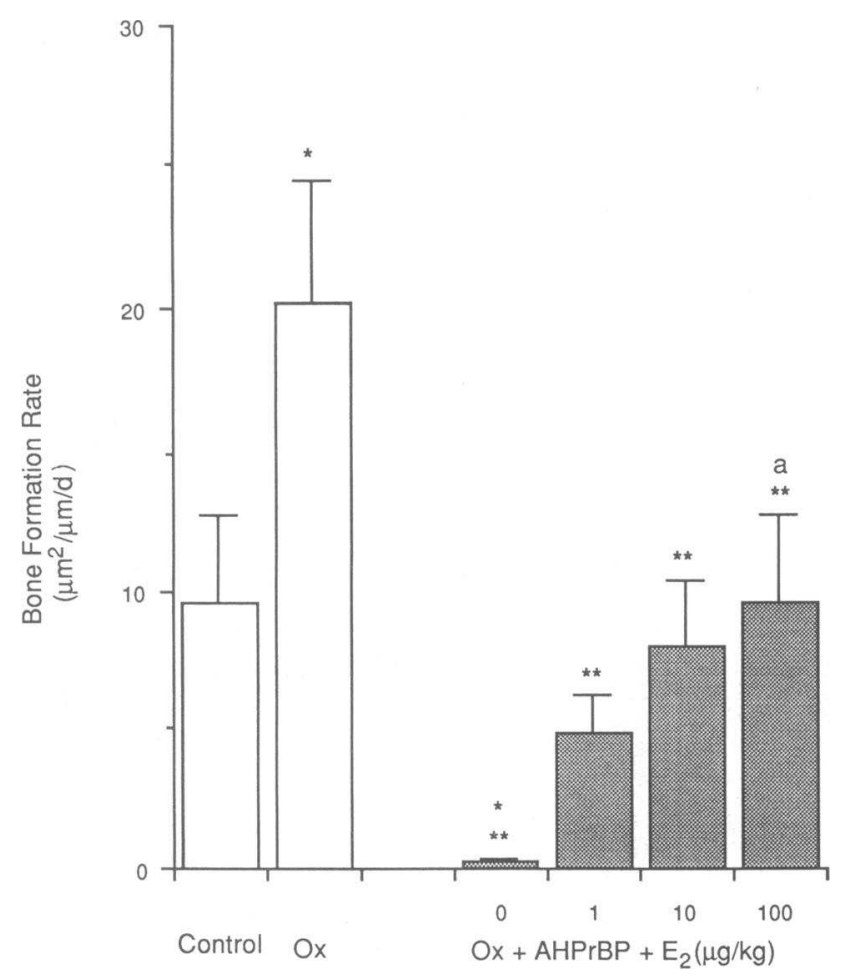

Figure 2. Effect of ovariectomy (Ox), AHPrBP, and $\mathrm{E}_{2}$ on bone formation rate at the proximal tibial metaphysis. Results are expressed in mean \pm SEM. *Significantly $(P<0.05)$ different from control; ** significantly different $(P<0.05)$ from $O x$; a, significantly $(P<0.05)$ different from Ox + AHPrBP. rate was significantly greater in animals treated with $100 \mu \mathrm{g} / \mathrm{kg}$ $\mathrm{E}_{2}$ than animals treated with AHPrBP alone (Fig. 2).

The osteoblast surface showed a parallel increase in ovariectomized animals, although this did not reach statistical significance. This was markedly suppressed with AHPrBP (Table III). The osteoblast surface in animals treated with $100 \mu \mathrm{g} / \mathrm{kg} \mathrm{E}$ was increased compared with those treated with AHPrBP alone, but this was not statistically significant. Hence the osteoblast surface appears to be a less sensitive parameter for bone formation than double-labeled surface. The osteoclast surface and number of osteoclasts per millimeter of bone surface was increased in ovariectomized animals, and decreased in animals treated with AHPrBP. There were no statistically significant differences in osteoclast number or surface between animals treated with $\mathrm{E}_{2}$ and those treated with AHPrBP alone.

Nonmetaphyseal bone. Ovariectomy and AHPrBP treatment did not appear to affect the longitudinal growth rate, but this was suppressed in a dose-dependent manner in $\mathrm{E}_{2}$-treated animals, (Table III). Although AHPrBP suppressed bone formation at the proximal metaphysis, we saw no effect on the periosteal and cortico-endosteal double-labeled surfaces or bone formation rate (Table IV). Similarly, there was no significant difference between $\mathrm{E}_{2}$-treated animals and those treated with AHPrBP alone with respect to these parameters (data not shown).

\section{Discussion}

It is well established that in ovariectomized and postmenopausal women there is an increase in bone turnover, associated with increased bone resorption and an increase in bone formation insufficient to compensate for increased bone resorption $(5,6,14-16)$. A similar sequence has been described in ovariectomized rats $(7,8)$. In accord with these observations, we found that the ovariectomized rats showed a substantial loss of metaphyseal bone despite an increase in bone formation.

In those ovariectomized rats that were also given AHPrBP, which inhibits bone resorption (17), bone loss was prevented. Metaphyseal bone formation was also inhibited. Suppression of bone resorption by bisphosphonates has been reported by others to inhibit bone formation in ovariectomized rats (18) and it is well established that suppression of bone resorption generally causes a reduction in bone formation (19). The suppression of bone formation by AHPrBP at the proximal metaphysis of our estrogen-deficient rats is unlikely to be due to direct interference by AHPrBP itself in bone formation, because bone formation was unaffected at the diaphysis, and was restored at the proximal metaphysis itself by estrogen replacement. Nor was increased fluorescent labeling in the presence of $E_{2}$ attributable to suppression of resorption of fluorescent label by $E_{2}$, because suppression of resorption by AHPrBP reduced fluorescent label, and further resorption suppression by $E_{2}$ would thus be expected to further reduce, rather than increase, fluorescent labeling.

Our results therefore suggest that, as expected, AHPrBP acted to inhibit bone formation at the proximal metaphysis through inhibition of bone resorption (suppression of bone turnover). The increase in bone volume that occurred with estrogen replacement in AHPrBP-treated animals, together with histodynamic evidence of bone formation, shows that after suppression of bone resorption, bone formation at the 
Table III. Effect of Ovariectomy (Ox), AHPrBP, and $E_{2}$ on Static and Dynamic Histomorphometry at the Proximal Tibial Metaphysis

\begin{tabular}{|c|c|c|c|c|c|c|}
\hline & \multicolumn{6}{|c|}{ Groups } \\
\hline & Control & Ox & $\mathrm{Ox}+\mathrm{AHPrBP}$ & $\mathrm{Ox}+\mathrm{AHPrBP}+1 \mu \mathrm{g} \mathrm{E}_{2}$ & $\mathrm{Ox}+\mathrm{AHPrBP}+10 \mu \mathrm{g} \mathrm{E}_{2}$ & $\mathrm{Ox}+\mathrm{AHPrBP}+100 \mu \mathrm{g} \mathrm{E}_{2}$ \\
\hline $\mathrm{Ob}$ S/BS (\%) & $1.4 \pm 0.7$ & $3.3 \pm 0.9$ & $0.9 \pm 0.6^{\ddagger}$ & $0.2 \pm 0.1$ & $0.8 \pm 0.4$ & $1.8 \pm 0.7$ \\
\hline Oc S/BS (\%) & $0.5 \pm 0.2$ & $2.0 \pm 0.5^{*}$ & $0.1 \pm 0.04^{\ddagger}$ & $0.3 \pm 0.1$ & $0.4 \pm 0.1$ & $0.4 \pm 0.1$ \\
\hline $\mathrm{N} \mathrm{Oc} / \mathrm{BS}(n / \mathrm{mm})$ & $0.1 \pm 0.03$ & $0.5 \pm 0.1^{*}$ & $0.1 \pm 0.03^{\ddagger}$ & $0.1 \pm 0.02$ & $0.1 \pm 0.03$ & $0.1 \pm 0.04$ \\
\hline $\operatorname{MAR}(\mu \mathrm{m} / \mathrm{d})$ & $1.5 \pm 0.3$ & $2.0 \pm 0.15$ & $0.1 \pm 0.1^{\ddagger}$ & $1.1 \pm 0.3^{8}$ & $1.5 \pm 0.2^{\S}$ & $1.2 \pm 0.2^{\S}$ \\
\hline $\mathrm{dL} / \mathrm{BS}(\%)$ & $5.8 \pm 1.5$ & $9.8 \pm 1.8$ & $0.15 \pm 0.15^{\ddagger}$ & $4.3 \pm 1.3$ & $5.4 \pm 1.3^{\S}$ & $7.4 \pm 2.3^{5}$ \\
\hline $\operatorname{LGR}(\mu \mathrm{m} / \mathrm{d})$ & $77.4 \pm 10.3$ & $77.9 \pm 7.3$ & $83.8 \pm 3.9$ & $86.5 \pm 2.6$ & $57.8 \pm 8.8^{8}$ & $53.1 \pm 4.1^{8}$ \\
\hline
\end{tabular}

Results are expressed as mean \pm SEM. Ob S, osteoblast surface; Oc S, osteoclast surface; N Oc/BS, osteoclast number per mm; MAR, mineral apposition rate; $\mathrm{dL}$, percentage of bone surface showing double fluorescent labels; $\mathrm{LGR}$, longitudinal growth rate. ${ }^{*}$ Significant (Ox vs Control) $(P<0.05) ;{ }^{\ddagger}$ significant $(\mathrm{Ox}+\mathrm{AHPrBP}$ vs Ox $)(P<0.05) ;{ }^{8}$ significant $\left(\mathrm{Ox}+\mathrm{AHPrBP}+\mathrm{E}_{2}\right.$ vs $\left.\mathrm{Ox}+\mathrm{AHPrBP}\right)(P<0.05)$.

proximal metaphysis is estrogen dependent, and that estrogen, at physiological concentrations, exerts an anabolic effect on bone at this site. It is possible, however, that a component of the increase in bone volume may be an additive inhibition of bone resorption by $E_{2}$ and $A H P r B P$.

Despite the dose-dependent anabolic effect of estrogen in the physiological range, bone formation rates were higher in ovariectomized rats than in animals administered even doses adequate for replacement. Consequently, after ovariectomy, the stimulation of bone formation consequent on increased bone resorption exceeds, and thus masks, the simultaneous reduction in estrogen-dependent bone formation. It appears that estrogen maintains bone mass not only through an antiresorptive effect but also through stimulation of bone formation.

We also noted that $E_{2}$ inhibited longitudinal bone growth due to a reduction in the growth of epiphyseal cartilage, as found by others $(8,20)$. The question arises of whether decreased longitudinal growth could contribute to the increased

Table IV. Effect of Ovariectomy $(O x)$ and AHPrBP on Static and Dynamic Histomorphometry at the Tibial Diaphysis

\begin{tabular}{lccr}
\hline & \multicolumn{3}{c}{ Group } \\
\cline { 2 - 4 } & Control & Ox & Ox + AHPrBP \\
\hline $\begin{array}{c}\text { Cross-sectional area } \\
\left(\mathrm{mm}^{2}\right)\end{array}$ & $4.5 \pm 0.2$ & $4.3 \pm 0.2$ & $4.3 \pm 0.2$ \\
Cortical area $\left(\mathrm{mm}^{2}\right)$ & $3.7 \pm 0.2$ & $3.6 \pm 0.1$ & $3.6 \pm 0.1$ \\
Medullary area $\left(\mathrm{mm}^{2}\right)$ & $0.8 \pm 0.03$ & $0.8 \pm 0.1$ & $0.8 \pm 0.1$ \\
Periosteal dL/BS $(\%)$ & $55.4 \pm 9.8$ & $54.3 \pm 11.3$ & $49.1 \pm 1.6$ \\
Periosteal MAR $(\mu \mathrm{m} / \mathrm{d})$ & $4.3 \pm 0.2$ & $3.3 \pm 0.2$ & $3.3 \pm 0.4$ \\
$\begin{array}{l}\text { Periosteal BFR } \\
\left(\mu \mathrm{m}^{2} / \mu \mathrm{m} \text { per d) }\right.\end{array}$ & $245.5 \pm 55.6$ & $179.6 \pm 35.0$ & $162.2 \pm 17.67$ \\
$\begin{array}{c}\text { Cortico-endosteal } \\
\text { dL/BS }(\%)\end{array}$ & $17.5 \pm 4.7$ & $23.1 \pm 3.8$ & $34.4 \pm 11.1$ \\
Cortico-endosteal MAR & & & \\
$\quad(\mu \mathrm{m} / \mathrm{d})$ & $2.0 \pm 0.3$ & $2.2 \pm 0.2$ & $2.0 \pm 0.3$ \\
Cortico-endosteal BFR & & & \\
$\left(\mu \mathrm{m}^{2} / \mu \mathrm{m}\right.$ per d) & $36.7 \pm 6.8$ & $51.0 \pm 7.9$ & $63.9 \pm 11.0$ \\
& & &
\end{tabular}

Results are expressed as mean \pm SEM. None of the differences reached statistical significance. dL, Percentage of surface showing double fluorochrome label; MAR, mineral apposition rate; BFR, bone formation rate. bone volume. One of the primary functions of longitudinal bone growth is to provide calcified cartilage cores as templates . for the formation of trabecular bone spicules. Inhibition of this process by $E_{2}$ would presumably result in a lower, rather than higher, bone volume. Nor could changes in longitudinal growth account for the increase in bone formation noted with $\mathrm{E}_{2}$ administration, because increased bone formation was observed even in animals treated with $\mathrm{E}_{2}$ in which longitudinal growth was unaffected.

Although estrogen clearly has a potent antiresorptive effect, which has made a separate anabolic effect difficult to identify, it seems reasonable that a hormone implicated in the maintenance of bone mass should be both anabolic and anticatabolic. In fact, there is evidence from other sources that supports an anabolic role for estrogen: ovariectomy in Beagle dogs has been found to reduce mean wall thickness (21), and estrogen increases proliferation and collagen production by bone cells in vitro $(22,23)$.

However, although estrogen is a potent antiresorptive agent, resorption clearly occurs in the presence of intact ovarian function, and can be inhibited further by agents such as bisphosphonates (17). This is consistent with our own results, in which AHPrBP maintained bone volume despite lack of detectable bone formation in ovariectomized rats; restoration of anabolism by estrogen replacement then induced a considerable increase in bone volume. This implies that suppression of resorption beyond that induced by physiological levels of estrogen, together with restoration of anabolism through estrogen replacement, may have a greater effect on bone volume than either bisphosphonate or estrogen alone in estrogen-deficiency states.

The anabolic effect of estrogen was achieved by a combination of an increase in osteoblast recruitment, as judged by an increase in the extent of trabecular surfaces showing double fluorochrome labeling, and an increase in the productivity of individual osteoblasts, as evidenced by an increase in the mineral apposition rate by $\mathrm{E}_{2}$ with $\mathrm{AHPrBP}$, compared to AHPrBP alone. Although both were increased, the pattern of results over the dose range of $E_{2}$ used suggests that increased recruitment may be the dominant mechanism by which $\mathrm{E}_{2}$ induces anabolism. This question is currently being further addressed. Osteoblast surfaces broadly reflected changes in double-labeled surfaces, but the proportion of bone surfaces lined by osteoblasts was less than that showing double label. This may be due to caution in counting as osteoblastic only those surfaces on 
which we were convinced that osteoblasts were present. A similar relationship between osteoblastic and double-labeled surfaces has been noted by other investigators (8). Double label is more objective and reliable, and we have based our conclusions largely on this.

The anabolic effect of estrogen seems to be specific for the metaphysis: no significant effect was observed at the diaphysis. This is consistent with the results of others who have found no decrease in cortical bone area in the diaphysis of ovariectomized rats, while the metaphysis becomes osteopenic following ovariectomy $(24,25)$, and also is consistent with the generally different responsiveness of dynamic histomorphometric parameters in metaphyseal and cortical bone to ovariectomy and hormone replacement $(7,25-28)$. Bone also accumulates in the metaphysis after PTH therapy $(29,30)$, during high dose estrogen therapy (31-34), and before egg production in birds (35). It is intriguing to speculate that estrogen may induce and maintain bone at this site as an estrogen-dependent quantum of bone (24) that is available as a metabolic reserve.

Although there is the reservation that the skeleton of the rat does not necessarily behave in a similar manner to the trabecular bone of man, at least some remodeling occurs (36), and the rat shows a similar skeletal response to ovariectomy and estrogen replacement $(7,8)$. It therefore seems possible that the anabolic role we have identified for estrogen, in addition to its known antiresorptive role, may be of relevance to the mechanisms by which bone is lost in estrogen-deficient states and to therapeutic approaches to this bone loss in women.

\section{Acknowledgments}

This work was supported by the Sir Jules Thorn Trust.

\section{References}

1. Richelson, L. S., H. W. Heinze, L. J. Melton III, and B. L. Riggs. 1984. Relative contributions of ageing and estrogen deficiency to postmenopausal bone loss. N. Engl. J. Med. 311:1273-1275.

2. Stevenson, J. C., B. Lees, M. Devenport, M. P. Cust, and K. F. Gangar. 1989. Determinants of bone density in normal women: risk factors for future osteoporosis? Br. Med. J. 298:924-928.

3. Ettinger, B., H. K. Genant, and C. E. Cann. 1985. Long-term estrogen replacement therapy prevents bone loss and fractures. Ann. Intern. Med. 102:319-324.

4. Lindsay, R., D. M. Hart, C. Forrest, and C. Baird. 1980. Prevention of spinal osteoporosis in oophorectomized women. Lancet. ii:1151-1153.

5. Christiansen, C., M. S. Christiansen, N.-E. Larsen, and I. Transbol. 1982. Pathophysiological mechanism of estrogen effect on bone metabolism: dose-response relationship in early postmenopausal women. J. Clin. Endocrinol. Metab. $55: 1124-1130$.

6. Stock, J. L., J. A. Coderre, and L. E. Mallette. 1985. Effects of a short course of estrogen on mineral metabolism in postmenopausal women. J. Clin. Endocrinol. Metab. 61:595-600.

7. Turner, R. T., J. J. Vandersteenhoven, and N. H. Bell. 1987. The effects of ovariectomy and $17 \beta$-estradiol on cortical bone histomorphometry in growing rats. J. Bone Miner. Res. 2:115-122.

8. Wronski, T. J., M. Cintron, A. L. Doherty, and L. M. Dann. 1988. Estrogen treatment prevents osteopenia and depresses bone turnover in ovariectomized rats. Endocrinology. 123:681-686.

9. Pilbeam, C. C., J. Klein-Nulend, and L. G. Raisz. 1989. Inhibition by $17 \beta$-estradiol of PTH-stimulated resorption and prostaglandin production in cultured neonatal mouse calvariae. Biochem. Biophys. Res. Commun. 163:13191324.
10. Takano-Yamamoto, T., and G. A. Rodan. 1990. Direct effects of 17 $\beta$ estradiol of trabecular bone in ovariectomized rats. Proc. Nat. Acad. Sci. USA. 87:2172-2176

11. Tobias, J. H., and T. J. Chambers. 1991. Effect of sex hormones on bone resorption by rat osteoclasts. Acta Endocrinol. 124:121-127.

12. Parfitt, A. M. 1984. The cellular basis of bone remodeling: the quantum concept reexamined in light of recent advances in the cell biology of bone. Calcif. Tissue Int. 36(Suppl):S37-S45.

13. Tobias, J. H., J. Chow, K. W. Colston, and T. J. Chambers. 1991. High concentrations of $17 \beta$-estradiol stimulate trabecular bone formation in adult female rats. Endocrinology. 128:408-412.

14. Stepan, J. J., J. Póspichal, J. Presl, and V. Pacovsky. 1987. Bone loss and biochemical indices of bone remodeling in surgically induced postmenopausal women. Bone (Elmsford). 8:279-284.

15. Barzel, U.S. 1988. Estrogens in the prevention and treatment of postmenopausal osteoporosis: a review. Am. J. Med. 85:847-850.

16. Riggs, B. L., and L. J. Melton III. 1986. Involutional osteoporosis. N. Engl. J. Med. 314:1676-1686.

17. Fleisch, H. 1982. Bisphosphonates: mechanisms of action and clinica applications. W. A. Peck, editor. Excerpta Med. Int. Congr. Ser. 1:319-357.

18. Movsowitz, C., S. Epstein, M. Fallon, F. Ismail, and S. Thomas. 1990 Hyperostosis induced by the bisphosphonate (2-PEBP) in the oophorectomized rat. Calcif. Tissue Int. 46:195-199.

19. Parfitt, A. M. 1982. The coupling of bone formation to bone resorption: a critical analysis of the concept and its relevance to the pathogenesis of osteoporosis. Metab. Bone Dis. \& Relat. Res. 4:1-6.

20. Tapp, E. 1966. The effects of hormones on bone in growing rats. J. Bone J. Surg. 48B:526-531.

21. Malluche, H. H., M.-C. Faugere, M. Rush, and R. M. Friedler. 1986. Osteoblastic insufficiency is responsible for maintenance of osteopenia after loss of ovarian function in experimental Beagle dogs. Endocrinology. 119:2649-2654.

22. Ernst, M., C. Schmid, and E. R. Froesch. 1988. Enhanced osteoblast proliferation and collagen gene expression by estradiol. Proc. Nat. Acad. Sci. USA. 85:2307-2310.

23. Komm, B. S., C. M. Terpening, D. J. Benz, K. A. Graeme, A. Gallegos, M. Korc, G. L. Greene, B. W. O'Malley, and M. R. Haussler. 1988. Estrogenic binding, receptor mRNA and biologic response in osteoblast-like osteosarcoma cells. Science (Wash. DC). 241:81-84.

24. Kimmel, D. B., and T. J. Wronski. 1990. Non-destructive measurement of bone mineral in femurs from ovariectomized rats. Calcif. Tissue Int. 46:101110.

25. Turner, R. T., E. R. Lifrak, M. Beckner, G. K. Wakley, K. S. Hannon, and L. N. Parker. 1990. Dehydroepiandrosterone reduces cancellous bone osteopenia in ovariectomized rats. Am. J. Physiol. 258:E673-E677.

26. Turner, R. T., K. S. Hannon, L. M. Demers, J. Buchanan, and N. H. Bell. 1989. Differential effects of gonadal function on bone histomorphometry in male and female rats. J. Bone Miner. Res. 4:557-563.

27. Kalu, D. N., C.-C. Liu, R. R. Hardin, and B. W. Hollis. 1989. The aged rat model of ovarian hormone deficiency bone loss. Endocrinology. 124:7-16.

28. Turner, R. T., D. S. Colvard, and T. C. Spelsberg. 1990. Estrogen inhibition of periosteal bone formation in rat long bones: down-regulation of gene expression for bone matrix proteins. Endocrinology. 127:1346-1351.

29. Hock, J. M., I. Gera, J. Fonsecq, and L. G. Raisz. 1988. Human parathyroid hormone-(1-34) increases bone mass in ovariectomized and orchidectomized rats. Endocrinology. 122:2899-2904.

30. Bauer, W., J. C. Aub, and F. Albright. 1929. Studies of calcium and phosphorus metabolism. N. Engl. J. Med. 49:145-151.

31. Liu, C. C., and G. A. Howard. 1991. Bone cell changes in oestrogen-induced bone mass increase in mice: dissociation of osteoclasts from bone surfaces. Anat. Rec. 229:240-250.

32. Budy, A. M., M. R. Urist, and F. C. McLean. 1952. The effect of oestrogens on the growth apparatus of the bones of immature rats. Am. J. Pathol. 280:1143-1167.

33. Urist, M. R., A. M. Budy, and F. C. McLean. 1950. Endosteal bone formation in estrogen-treated mice. J. Bone J. Surg. 32A:143-162.

34. Day, H. C., and R. H. Follis. 1941. Skeletal changes in rats receiving estradiol benzoate as indicated by histological studies and determinations of bone ash, serum calcium and phosphatase. Endocrinology. 28:83-93.

35. Silberberg, M., and R. Silberberg. 1971. Steroid hormones and bone. In The Biochemistry and Physiology of Bone. C. H. Bourne, editor. Academic Press Inc., New York/London. Vol. III:401-442.

36. Baron, R., R. Tross, and A. Vignery. 1984. Evidence of sequential remodeling in rat trabecular bone: morphology, dynamic histomorphometry, and changes during skeletal maturation. Anat. Rec. 208:127-145. 